\title{
Documentary Records of Past Climate and Tropical Cyclones from the Southeastern United States
}

\author{
CARY J. Mock \\ Department of Geography, University of South Carolina, Columbia, South Carolina, USA; mockcj@sc.edu
}

Climatic changes at interannual and decadal timescales are of important concern to residents of the Southeastern United States. This region has a low water-storage capacity and is extraordinarily susceptible to prolonged drought and fire hazards. Superimposed within interannual climatic variations are high-magnitude flood, snowstorm, and hurricane hazards that occur at daily to weekly timescales. Winter polar outbreaks and killing frosts also occasionally occur, severely impacting the fruit tree industry (Stahle, 1990). Modern climate studies indicate that teleconnections, such as ENSO, the PNA, and the NAO, substantially influence southeastern U.S. climate. A longer perspective is critical to fully investigate the temporal and spatial stability of these important modes of climatic variability.

Documentary weather records are available for several areas of the Southeastern United States for the past several hundred years prior to the establishment of the first organized weather bureau in 1871. These records include hundreds of plantation diaries, numerous newspapers, and early instrumental records. The first systematic meteorological observations conducted in the United States began in Charleston, South Carolina in 1838 by Dr. John Lining (Aldredge, 1940). The abundant climatic details of plantation manuscripts for the Southeast are well-known to historians, with many daily records containing weather observations. Yet, despite their huge potential, manuscripts in the Southeast have only been recently utilized for climate reconstruction.

Clearly, the reliability of historical reports cannot be taken at face value, with some materials actually being inappropriate for climate reconstruction. Original sources were used if available, as typescript copies may contain erroneous edited information. Written descriptions of severe storms and climate may also reflect

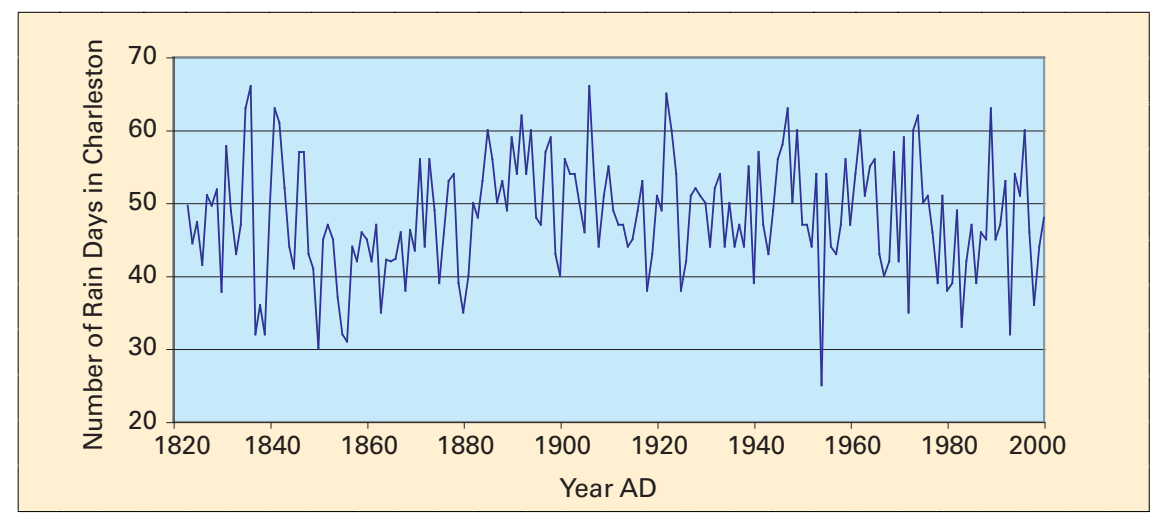

Fig. 1: Annual June-September precipitation frequencies for Charleston, South Carolina, USA. The horizontal reference line indicates the modern climatic normal of rain days from 1971-2000.

individual biases from diarists. Daily historical data were collected whenever possible in order to properly assess data quality, as these data reveal important aspects such as diurnal temperature ranges and the timing of precipitation events. Discontinuities were searched carefully in time series of greater than ten years, and any suspect data were not included in our reconstructions. A major goal of our research was to calibrate and present historical climate data in a format that is closely compatible with the modern record.

Two examples of historical reconstructions for Charleston, South Carolina are presented in the following: 1) June-September (warm-season) precipitation frequency and 2) tropical cyclone frequency. Precipitation frequencies from both early instrumental and documentary evidence are among the most reliable and plentiful climatic indicators for the historical climatologist, as these reconstructions can be directly compared with modern climatic data (Mock, 1991). Precipitation frequencies also more accurately reflect homogeneous signals that respond to changes in synoptic-scale atmospheric circulation (Woodhouse and Meko, 1997). With plentiful documentary data within the city limits, Charleston presents an ideal location to reconstruct frequencies of measurable precipitation, defined as days on which precipitation was at least $0.0254 \mathrm{~cm}$ (0.01 inches). The Charleston tropical cyclone frequency record is the longest of its kind that is reconstructed for a location in the United States. Its record is continuous since 1778, augmenting the Atlantic Basin historical hurricane database (Fernández-Partagás and Diaz, 1996).

A complete reconstruction of June-September precipitation frequencies for Charleston extends back to 1823 (Fig. 1). The twentieth century record reveals both interannual and decadal variability, with somewhat greater precipitation during most of the first half of the twentieth century. A distinctive period of lower precipitation is evident for much of the period from 1845-1870, and this activity is unprecedented relative to the twentieth century record. Such a persistent period of drought most likely had dramatic climate impacts on the antebellum plantation agriculture and lifestyle. Although underestimation of precipitation is a common problem in historical climatic reconstructions, the author is confident that this is not a problem for the 1845-1870 period, as the quality of the documentary data is clearly superior and more plentiful than the relatively wetter pre-1845 period.

Results of the tropical cyclone frequency reconstruction for Charleston are displayed for each year and by a 5-year centered moving average (Fig. 2). The number of storms per 


\section{Science Highlights}

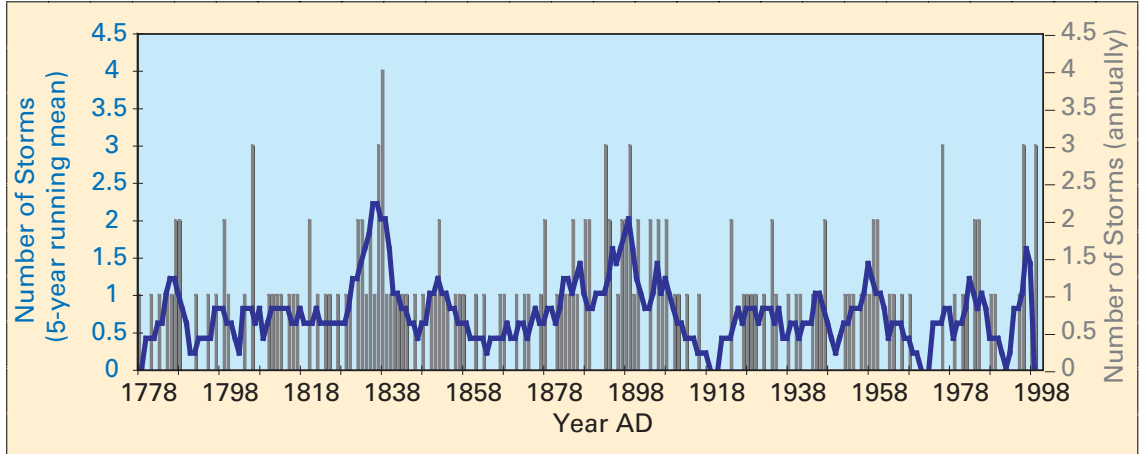

Fig. 2: Time series of tropical cyclone frequencies for South Carolina, centered at Charleston, from 1778-2000. The red vertical bars represent annual frequencies while the blue line represents a 5-year running mean.

year varied from zero to four, but mostly from zero to two. Details of 68 storms were analyzed for the 1778-1870 period, with 25 of them being newly documented storms. A calculated mean recurrence interval for 1778-1870 suggests significant tropical storm impact on Charleston every 1.30 years, clearly lower than the interval of 1.80 years that dominates during most of the late nineteenth and twentieth centuries. The 5-year running mean indicates that much of this greater tropical cyclone activity occurred in the 1830s. This decade is clearly the most active in the entire time series. In particular, 1838 had four storms, the most annually for the entire record, and two of the four storms occurred in June.

Documentary evidence of the Southeastern United States, although not as lengthy as in Europe and Asia, provides valuable information of high resolution climate back into the eighteenth century, well before the modern instrumental record. It contributes to other existing high resolution paleoclimatic and paleohurricane databases for North America, providing further insight on the spatial variations and causes of natural climatic variability. Aside from tree-rings, that are sensitive mostly to late-spring rainfall and drought, these historical data are the only evidence of past climate that can provide seasonal quantitative reconstructions for the region. Historical climate records from the Southeastern United States can also aid in testing and verifying general circulation model simulations of the past several centuries.

\section{References}

Aldredge, R.C. 1940: Weather observers and observations at Charleston, South Carolina from 16701871. Historical Appendix of the Year Book of the City of Charleston for the Year 1940: 190-257.

Fernández-Partagás, J. and Diaz, H.F., 1996: Atlantic hurricanes in the second half of the nineteenth century. Bulletin of the American Meteorological Society, 77: 2899-2906.

Mock, C.J., 1991: Historical evidence of a cold dry summer in the northeastern Great Basin and adjacent Rocky Mountains during the summer of 1849. Climatic Change, 18: 37-66

Stahle, D.W., 1990: The Tree-Ring Record of False Spring in the Southcentral United States. Ph.D. Dissertation, Arizona State University. Tempe, AZ, U.S.A.

Woodhouse, C.A. and Meko, D.M., 1997: Number of winter precipitation days reconstructed from Southwestern tree rings. Journal of Climate $\mathbf{1 0}$ 2663-2669.

\section{Floods in Europe - A Look into the Past}

Rudolf Brázdil ${ }^{1}$, Rüdiger Glaser ${ }^{2}$, Christian Pfister ${ }^{3}$ and Heiko Stangl ${ }^{2}$

${ }_{1}^{1}$ Department of Geography, Masaryk University, Brno, The Czech Republic; brazdil@sci.muni.cz

2 Department of Geography, University of Heidelberg, Germany; ruediger.glaser@urz.uni-hd.de; heiko.stangl@urz.uni-hd.de

3 National Center of Competence in Research on Climate (NCCR), Institute of History, University of Bern, Switzerland; pfister@hist.unibe.ch

During the 1990s, floods (e.g. 1993 and 1995 on the Rhine and the Meuse, 1997 on the Morava and the Oder and 2002 in Central Europe) have been among the most devastating disasters in Europe resulting in losses of human lives and substantial damage, disrupting community life and generating collective stress and widespread fear. The deluge of August 2002 in Central Europe caused such staggering losses that Germany's large economy has struggled to cope with the costs of recovery. The issue of whether and how such disasters might be related to the greenhouse effect and global warming is repeatedly put on the agenda. However, the number of well-documented cases is too small for conclusions to be drawn. In Europe, early water gauge measurements started during the eighteenth century (e.g.
1708 in Zurich) but for most rivers, instrumental observations are only available for the twentieth century. This is insufficient for an assessment of flood frequency changes in the presence of substantial natural climate variability. Documentary evidence about severe flood events can substantially increase the number of cases available for analysis.

\section{Documentary evidence on floods}

Two types of evidence - written reports and flood marks - need to be distinguished.

Reports on severe floods go back to the Middle Ages. They are documented in sources such as annals, chronicles, memoirs, diaries, letters, newspapers or economic records. For example, the first reliable report about a flood in Prague was written by the chronicler Kosmas (Brázdil,
1998): "In the year of our Lord 1118 in the month of September there was such a flood as, I think, it has not been on the Earth since the Deluge. This river of ours, the Vltava, suddenly broke out of its bed - how many villages, how many houses in the suburbs, huts and churches did it take away! At other times, although it happens rarely, the water reaches only the floor of the bridge, but this flood rose to a height of ten ells [i.e. approximately $6 \mathrm{~m}$ ] over the bridge." This chronicler tried to quantify the magnitude of the event by relating the highest water level to the altitude of the bridge (one of the predecessors of the recent wellknown Charles bridge).

Some reports just mention the occurrence of an event. Others may include description on the causes of the flood, its magnitude and duration as well as detailed accounts on 